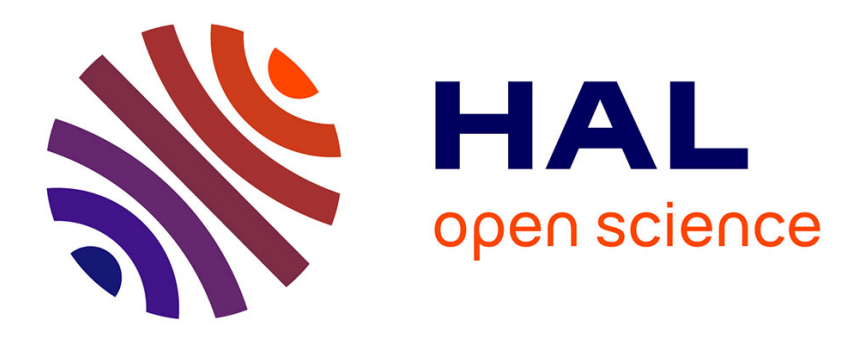

\title{
Identification of intermediate pathways of 4-hydroxynonenal metabolism in the rat
}

J. Alary, Y. Fernandez, Laurent Debrauwer, Elisabeth Perdu, Françoise

Guéraud

\section{- To cite this version:}

J. Alary, Y. Fernandez, Laurent Debrauwer, Elisabeth Perdu, Françoise Guéraud. Identification of intermediate pathways of 4-hydroxynonenal metabolism in the rat. Chemical Research in Toxicology, 2003, 16, pp.320-327. 10.1021/tx025671k . hal-02682569

\section{HAL Id: hal-02682569 \\ https://hal.inrae.fr/hal-02682569}

Submitted on 1 Jun 2020

HAL is a multi-disciplinary open access archive for the deposit and dissemination of scientific research documents, whether they are published or not. The documents may come from teaching and research institutions in France or abroad, or from public or private research centers.
L'archive ouverte pluridisciplinaire HAL, est destinée au dépôt et à la diffusion de documents scientifiques de niveau recherche, publiés ou non, émanant des établissements d'enseignement et de recherche français ou étrangers, des laboratoires publics ou privés. 


\title{
Identification of Intermediate Pathways of 4-Hydroxynonenal Metabolism in the Rat
}

\author{
J acques Alary, ${ }^{\dagger}$ Yvette Fernandez, $^{\ddagger}$ Laurent Debrauwer, ${ }^{\dagger}$ Elisabeth Perdu, $^{\dagger}$ and \\ Françoise Guéraud*,† \\ Laboratoire des Xénobi otiques, UMR 1089, I NRA-I nstitut National de la Recherche Agronomique, \\ 180 Chemin de Tournefeuille, BP3, 31931 Toulouse Cedex 9, France, and Laboratoire de \\ Neurobiologie, Plasticité Tissulaire et Métabolisme É nergétique, UMR 5018, CNRS-Institut de \\ Recherche Louis Bugnard-IFR31, CHU Rangueil, Bât L1, 31403 Toulouse Cedex 4, France
}

Received November 29, 2002

\begin{abstract}
The formation of 4-hydroxy-2-nonenal (HNE) conjugates with glutathione (GSH) by Michael addition and subsequent cleavage to yield the related mercapturic acid (MA) conjugates are a major detoxication process. To characterize the metabolic pathways involved in the formation of urinary $\mathrm{HNE}-\mathrm{MA}$ conjugates in the rat, the metabolism of $\mathrm{HNE}$-thioethers (HNE-GSH, $\mathrm{HNE}-\mathrm{MA}$, and HNE-Cys) by rat liver and kidney cytosolic fractions was investigated. The experimental results showed that HNE-GSH is a good substrate for cytosolic incubations whereas HNE-MA and HNE-Cys are poorly metabolized. About $80 \%$ of the urinary MA conjugates originate from the primary and major HNE metabolite, namely, the hemiacetalized HNE-GSH. The direct reduction of HNE-GSH by a cytosolic aldo-keto reductase (NADPH) leads to 1,4-dihydroxynonene-GSH (DHN-GSH) and subsequently to DHN-MA. The direct oxidation of HNE-GSH by aldehyde dehydrogenase (NAD) ${ }^{+}$leads to 4-hydroxynonenoiclactone-GSH, the partial hydrolysis of which occurs at physiological pH and accounts for the corresponding 4-hydroxynonenoic-GSH. Both the spontaneous- and the glutathione Stransferases-catalyzed retro-Michael cleavages of HNE-GSH and HNA-lactone-GSH are the source of HNE and HNA-lactone, respectively. This latter compound, with both lipophilic and electrophilic properties, is available for microsomal $\omega$-hydroxylation by cytochrome P450 4A enzymes and conjugation with thiol groups and therefore is the most likely candidate for the formation of $\omega$-hydroxylated HNE-mercapturic acid conjugates excreted in rat urine.
\end{abstract}

\section{Introduction}

$\mathrm{HNE}^{1}$ is a major aldehydic product resulting from the in vivo lipoperoxidation of membrane and lipoprotein $\omega-6$ unsaturated fatty acids ( $1-3)$. This compound, considered as a "second toxic messenger of oxygen free radicals" is cytotoxic, possibly genotoxic, and responsible for enzyme inactivation (ref 4 and for reviews, see refs 5 and 6). Its high reactivity is expected to be at least partially responsible for the damages observed in free radical pathology. Nevertheless, this compound can also act as a bioactive molecule in either physiological or pathological conditions such as excessive fibrogenesis in various chronic diseases, inflammatory reactions, or neuronal degeneration and may participate in gene expression regulation, cell signaling, and growth (for recent reviews, see refs 7-10). The main defense system against HNE toxicity is the capability of the cells to inactivate this alkenal by various biotransformation pathways, which are not completely elucidated yet.

When administered in vivo, labeled HNE is rapidly metabolized and mainly excreted into urine $(11,12)$ as a

\footnotetext{
* To whom correspondence should be addressed. Tel: 33(0)561 285 383. Fax: 33(0)561 285 244. E-mail: fgueraud@toulouse.inra.fr.

† INRA-Institut National de la Recherche Agronomique.

‡ CNRS-Institut de Recherche Louis Bugnard-IFR31.

1 Abbreviations: HNE, 4-hydroxy-2,3-trans-nonenal; GSH, glutathione; MA, mercapturic acid; DHN, 1,4-dihydroxynonene; HNA, 4-hydroxynonenoic acid; GST, glutathione S-transferase; ESI, electrospray ionization; $A D H$, alcohol dehydrogenase; ALDH, aldehyde dehydrogenase; AKR, aldo-keto reductase; SPE, solid phase extraction.
}

polar group of free $\omega$-oxidized metabolites from HNA and their MA conjugates and a group of less polar MA thioethers originating from the metabolism of the aldehyde moiety. After iv administration of $\mathrm{HNE}$, these two groups of metabolites accounted for $40-50$ and $30 \%$ of the injected dose, respectively (11). This pattern indicates that both oxidation reactions and GSH conjugation are the main metabolic pathways for HNE metabolization. Moreover, in vitro studies concerning HNE metabolism performed with isolated hepatocytes $(13,14)$, hepatoma cells (15), enterocytes (16), erythrocytes (17), liver slices (18), and perfused organs such as liver, kidney, and heart $(17,19,20)$ suggest that HNA and HNE-GSH account for the major and primary metabolites of HNE. The current study was undertaken in order to (i) give a more precise insight into the different pathways involved in the formation of HNE urinary metabolites, (ii) determine the role of liver and kidney in the biotransformation of this compound, and (iii) tentatively identify the enzymes involved in HNE metabolism. Therefore, the parent HNE - GSH and the two thioether derivatives HNE - Cys and $\mathrm{HNE}-\mathrm{MA}$ were incubated with rat liver and kidney cytosolic fractions. In addition, HNA-lactone was incubated with rat liver microsomes to investigate the possible implication of $\omega$-hydroxylation, as it was previously shown that microsomal P450 4A isozymes were involved in the metabolization of HNE in mice and that these metabolites originating from $\omega$-oxidation represent a large amount of urinary metabolites $(21,22)$. 


\section{Materials and Methods}

Chemicals. Silicagel 60 TLC plates $(0.25 \mathrm{~mm}, 5 \mathrm{~cm} \times 20$ $\mathrm{cm}$ ) were purchased from Merck (Nogent-sur-Marne, F rance). Disulfiram, pyrazole, phenobarbital, NADH, NADPH, and GSTs from rat liver (EC 2.5.1.18) were purchased from Sigma (Saint Quentin-Fallavier, France).

All solvents and reagents used for the preparation of buffers and HPLC eluents were of the highest purity grade available from Merck. Ultrapure water from Milli-Q system (Millipore, Saint Quentin en Yvelines, France) was used for HPLC eluent preparation.

HNE, DHN, HNA, DHN-GSH, HNA-MA, HNA-lactone$M A$, and DHN-MA were synthesized as previously described $(11,23)$. HNA-lactone-GSH was synthesized as $9 \mathrm{OH}-\mathrm{HNA}-$ lactone-MA (21), using GSH instead of N-acetylcysteine. HNAlactone was obtained by retro-Michael cleavage of HNAlactone-GSH catalyzed by GSTs.

[4- ${ }^{3} \mathrm{H}$ ]HNE (purity > 95\%; specific activity, $222 \mathrm{GBq} / \mathrm{mmol}$ ) was synthesized at CEA (Service des Molécules Marquées-CEN, Saclay, France) as diethylacetal, according to the method developed in our laboratory (24).

HPLC. The HPLC system consisted of a 420 Kontron pump (Zurich, Switzerland) equipped with a $500 \mu \mathrm{L}$ loop and a Hypersil ultrabase ODS column ( $5 \mu \mathrm{m}, 250 \mathrm{~mm} \times 7 \mathrm{~mm})$ from Shandon (Eragny, France) protected by a precolumn (Kromasil C18, $10 \mu \mathrm{m}$ ) and connected to a Gilson 202 fraction collector (Gilson, Villiers-le-Bel, France).

All of the experiments were carried out at room temperature $\left(19-22^{\circ} \mathrm{C}\right)$. The mobile phases were delivered at $2.3 \mathrm{~mL} / \mathrm{min}$, and the fractions were collected in 4 tubes/min.

The separation of HNE-GSH metabolites was performed using a two step elution with a mobile phase containing $15 \%$ acetonitrile and $85 \%$ acetic acid $(1 \%, \mathrm{v} / \mathrm{v})$ for $37.5 \mathrm{~min}$ and then a mobile phase containing $30 \%$ acetonitrile and $70 \%$ water for $22.5 \mathrm{~min}$.

For the separation of HNE - MA and HNE-Cys metabolites, a two step elution was used with a mobile phase containing $20 \%$ acetonitrile and $80 \%$ acetic acid $(1 \%, v / v)$ for $45 \mathrm{~min}$ and then a mobile phase containing $30 \%$ acetonitrile and $70 \%$ water for 30 $\min$.

MS. ESI/MS analysis was carried out on a Nermag R-10-10-H single quadrupole instrument (Delsi Nermag Instruments, Argenteuil, France) fitted with an Analytica ESI source (Branford, CT) and on a Finnigan LCQ quadrupole ion trap mass spectrometer equipped with the Finnigan ESI source (Thermo Finnigan, Les Ulis, France). The conditions applied to the Analytica ESI source were as follows: needle, ground potential; surrounding electrode, $-2500 \mathrm{~V}$; end plate/nozzle, $-3500 \mathrm{~V}$; metallized inlet end of the glass transfer capillary, $-4500 \mathrm{~V}$. Those applied to the ESI Finnigan source were as follows: needle, $-4500 \mathrm{~V}$; heated transfer capillary, 5-20 V. Structural information was obtained by carrying out $\mathrm{MS}^{n}$ experiments on the LCQ instrument under automatic gain control conditions and using helium as the collision gas. I on isolation and collision conditions were optimized separately for each metabolite to gain maximal structural information.

GC/MS analysis was performed on a Nermag R-10-10-T single quadrupole instrument coupled to a Delsi DI 200 (Delsi Nermag Instruments) gas chromatograph fitted with a BPX5 (25 m $\times$ $0.22 \mathrm{~mm} \times 0.2 \mu \mathrm{m}$ ) capillary column (SGE, Villeneuve Saint Georges, France). The samples were injected in the splitless mode. Helium was used as the carrier gas at a flow rate of 1 $\mathrm{mL} / \mathrm{min}$ with a back pressure of 0.8 bar. The oven temperature was programmed as follows: $50^{\circ} \mathrm{C}$ for $50 \mathrm{~s}$, and then from 50 to $230{ }^{\circ} \mathrm{C}$ at $25^{\circ} \mathrm{C} / \mathrm{min}$, and from 230 to $270{ }^{\circ} \mathrm{C}$ at $5{ }^{\circ} \mathrm{C} / \mathrm{min}$. The injector and interface temperature were $270{ }^{\circ} \mathrm{C}$. EI mass spectra were generated at $70 \mathrm{eV}$ with an emission current of $200 \mu \mathrm{A}$ at a source temperature of $220^{\circ} \mathrm{C}$.

Derivatization for GC/MS Analysis. The dry extracts were methylated by addition of $50 \mu \mathrm{L}$ of etheral diazomethane. After $30 \mathrm{~min}$ at room temperature, the solvent was removed under a nitrogen stream. The residue was then dissolved in a mixture of $\mathrm{N}, \mathrm{O}$-bis-trifluoroacetami de/trimethylchlorosilane (Pierce Chemical, Rockford, IL ) in a 99:1 ratio and heated at $60^{\circ} \mathrm{C}$ for $1 \mathrm{~h}$. The solvent was evaporated at $30^{\circ} \mathrm{C}$ under nitrogen stream, and hexane $(20 \mu \mathrm{L})$ was added to the residue. One microliter of the solution was injected into the gas chromatograph.

Synthesis of HNE-Thioether Conjugates. HNE-GSH and $\mathrm{HNE}-\mathrm{MA}$ were synthesized by reaction of $\mathrm{HNE}(0.06 \mathrm{mmol}$, $0.4 \mathrm{MBq})$ with L-GSH or $\mathrm{N}$-acetyl-L-Cys $(0.1 \mathrm{mmol})$ in $5 \mathrm{~mL}$ of $0.1 \mathrm{M}$ sodium phosphate buffer, $\mathrm{pH} 7.5$, at $37{ }^{\circ} \mathrm{C}$ overnight. Unreacted HNE was vortex-extracted with $4 \times 5 \mathrm{~mL}$ dichloromethane, and the aqueous phase was brought to $\mathrm{pH} 1-2$ (1 $\mathrm{M} \mathrm{H}_{3} \mathrm{PO}_{4}$ ) and applied to a $1 \mathrm{~g} \mathrm{C} 18$ cartridge (Supelco, Saint Quentin-Fallavier, France). The cartridge was washed with 20 $\mathrm{mL}$ of $1 \%(\mathrm{v} / \mathrm{v})$ acetic acid, dried with a nitrogen stream, and then eluted with $10 \mathrm{~mL}$ of methanol. HNE-Cys was synthesized as follows: stoichiometric amounts of racemic HNE $(0.06 \mathrm{mmol}$, $0.4 \mathrm{MBq}$ ) and L-Cys were reacted in water $(\mathrm{pH} 7.5)$ under $\mathrm{N}_{2}$ at $37{ }^{\circ} \mathrm{C}$ overnight. The reaction mixture was then treated as described for HNE-GSH and HNE-MA. The three thioether conjugates were characterized by ESI/MSn.

HNE-GSH is present as a cyclic hemiacetal $(25,26)$, and it is likely that this cyclic structure also occurs in HNE-MA and HNE-Cys. HNE - GSH and HNE - MA conjugates consisted of four HPLC resolved diastereoisomers, while HNE-Cys diastereoisomers remained partially unresolved (results not shown). ${ }^{1} \mathrm{H}$ and ${ }^{13} \mathrm{C}$ NMR showed that each diastereoisomer consisted of a pair of enantiomers.

Radioactivity Determination. The samples (cytosolic supernatants and HPLC fractions) were counted in a model 4330 Packard Tricarb scintillation counter (Packard Instrument Co., Downers Grove, IL) with Ultimagold (Packard) as the scintillation cocktail.

Cytosolic Incubations. Wistar rat liver and kidney cytosols were prepared as previously described (27). Protein concentrations were determined by the method of Lowry (28). All of the incubations were performed in $25 \mathrm{~mL}$ Corex centrifuge tubes in a shaking water bath at $37^{\circ} \mathrm{C}$ under nitrogen for $2 \mathrm{~h}$. Control incubations consisted of $0.1 \mathrm{M}$ sodium phosphate buffer ( $\mathrm{pH} 7.5$ ) containing $2.5 \mathrm{mg}$ of liver or kidney cytosolic proteins and the thioether substrate $(0.2 \mu \mathrm{mol}, 2 \mathrm{KBq})$. Some incubations were supplemented with $0.5 \mu \mathrm{mol}$ NADPH or $0.5 \mu \mathrm{mol} \mathrm{NADH}$ in 0.1 $\mathrm{mL}$ of $0.1 \mathrm{M}$ sodium phosphate buffer ( $\mathrm{pH} 7.5$ ). For the incubations performed in the presence of inhibitors, pyrazole or phenobarbital were added at a final concentration of 10 and $1 \mathrm{mM}$, respectively. The inhibition of ALDH by disulfiram was performed as follows: sodium phosphate buffer containing 2.5 $\mathrm{mg}$ of cytosolic proteins ( $2 \mathrm{~mL}$ final volume) was added with 10 $\mu \mathrm{L}$ of a $20 \mathrm{mM}$ disulfiram solution in dimethyl sulfoxide, and the sample was preincubated for $30 \mathrm{~min}$ at $37^{\circ} \mathrm{C}$. The resulting sample was then added with the thioether substrate and again with $10 \mu \mathrm{L}$ of a $20 \mathrm{mM}$ disulfiram solution (giving a final concentration of $0.2 \mathrm{mM}$ disulfiram) and incubated for $2 \mathrm{~h}$ at $37^{\circ} \mathrm{C}$.

Analysis of HNE - Thioether Conjugate Metabolites. The cytosolic incubation mixtures were vortex-extracted with $4 \mathrm{~mL}$ of dichloromethane and centrifuged (10 000 g for $5 \mathrm{~min}$ ). The dichloromethane phase was recovered and filtered on a Separation Phase Filter (Whatman SP1, Whatman, Maidstone, U.K.). This treatment was repeated three times. The combined dichloromethane extracts were concentrated to $1 \mathrm{~mL}$ under vacuum at room temperature, and a $20 \mu \mathrm{L}$ aliquot was counted. The dichloromethane extract was concentrated again to about 100 $\mu \mathrm{L}$ and applied to an activated $\left(120^{\circ} \mathrm{C}, 20 \mathrm{~min}\right) \mathrm{TLC}$ plate, which was developed with toluene/ethyl acetate (80:20). The radioactive spots were detected with a TLC Linear Analyzer LB 2832 (Berthold France, La Garenne Colombes, France) and scraped off. The silica was extracted with dichloromethane or dichloromethane/methanol (90:10), and the analytes were characterized by $\mathrm{ESI} / \mathrm{MS}^{n}$ or $\mathrm{GC} / \mathrm{MS}$.

The aqueous phase was gassed off with a nitrogen stream to remove dichloromethane traces. The aqueous sample was added with $4 \mathrm{vol}$ of methanol and placed at $0{ }^{\circ} \mathrm{C}$ for $15 \mathrm{~min}$ to 
Table 1. Metabolites Amounts Obtained with Rat Liver and Kidney Cytosolic Fractions with Three Different HNE - Thioethers as Substrate, Expressed as the Percentage of the Substrate Dose ${ }^{a}$

\begin{tabular}{|c|c|c|c|c|}
\hline metabolite & $\begin{array}{c}\text { proposed } \\
\text { identification }\end{array}$ & $\begin{array}{l}\text { identification } \\
\text { method }\end{array}$ & $\begin{array}{l}\% \text { with liver } \\
\text { cytosol }\end{array}$ & $\begin{array}{c}\% \text { with kidney } \\
\text { cytosol }\end{array}$ \\
\hline & & HNE-GSH & & \\
\hline $\begin{array}{l}\text { aqueous phase } \\
\text { G1 } \\
\text { G2 } \\
\text { G3 } \\
\text { G4 } \\
\text { G5 } \\
\text { G6 } \\
\text { G7 }\end{array}$ & $\begin{array}{l}\text { DHN-Cys } \\
\text { HNE-Cys } \\
\text { DHN-GSH } \\
\text { HNE-GSH } \\
\text { HNA-lactone-Cys } \\
\text { HNA-lactone-GSH } \\
\text { HNA }\end{array}$ & $\begin{array}{l}\text { ESI/MS } \\
\text { ESI/MS (18) } \\
\text { ESI/MS } \\
\text { ESI/MS (18) } \\
\text { ESI/MS } \\
\text { ESI/MS } \\
\text { GC/MS (methylation } \\
\text { and silylation) }\end{array}$ & $\begin{array}{r}1.7 \pm 0.5 \\
1.4 \pm 0.4 \\
6.7 \pm 1.5 \\
22.0 \pm 1.5 \\
2.4 \pm 0.4 \\
23.9 \pm 5.3 \\
3.5 \pm 0.8\end{array}$ & $\begin{array}{r}3.4 \pm 0.4 \\
3.7 \pm 0.7 \\
5.0 \pm 0.8 \\
25.5 \pm 4.0 \\
4.6 \pm 0.7 \\
25.3 \pm 6.6 \\
4.4 \pm 1.0\end{array}$ \\
\hline $\begin{array}{l}\text { organic phase } \\
\text { G8 ( }\left(R_{f} 0.02\right) \\
\text { G9 }\left(R_{f} 0.26\right) \\
\text { G10 }\left(R_{f} 0.52\right)\end{array}$ & $\begin{array}{l}\text { DHN } \\
\text { HNE } \\
\text { HNA-lactone }\end{array}$ & $\begin{array}{l}\text { GC/MS (silylation) } \\
\text { GC/MS (silylation) } \\
\text { ESI/MS }\end{array}$ & $\begin{array}{r}4.2 \pm 0.6 \\
10.2 \pm 0.7 \\
11.1 \pm 0.8\end{array}$ & $\begin{array}{l}3.5 \pm 0.8 \\
7.8 \pm 0.9 \\
9.5 \pm 1.2\end{array}$ \\
\hline \multicolumn{5}{|c|}{ HNE-MA } \\
\hline $\begin{array}{l}\text { M1 } \\
\text { M2 } \\
\text { M3 } \\
\text { M4, M5 } \\
\text { M6 } \\
\text { M7 } \\
\text { M8 } \\
\text { M9 }\end{array}$ & $\begin{array}{l}\text { HNE-Cys } \\
\text { HNA-lactone-GSH } \\
\text { DHN-MA } \\
\text { HNE-MA } \\
\text { DHN } \\
\text { HNA } \\
\text { HNA-lactone-MA } \\
\text { HNE }\end{array}$ & $\begin{array}{l}\text { ESI/MS (18) } \\
\text { ESI/MS } \\
\text { ESI/MS } \\
\text { ESI/MS } \\
\text { comp. with std } \\
\text { comp. with std } \\
\text { comp. with std } \\
\text { GC/MS }\end{array}$ & $\begin{array}{l}7.4 \pm 1.8 \\
<2 \\
<1 \\
81 \pm 2.0 \\
<2 \\
<2 \\
<2 \\
3.1 \pm 0.8\end{array}$ & $\begin{array}{l}21.1 \pm 2.3 \\
<2 \\
<1 \\
63.5 \pm 3.8 \\
<2 \\
3.3 \pm 0.5 \\
<2 \\
3.7 \pm 0.9\end{array}$ \\
\hline \multicolumn{5}{|c|}{ HNE-Cys } \\
\hline $\begin{array}{l}\text { C1 } \\
\text { C2 } \\
\text { C3 } \\
\text { C4 } \\
\text { C5 } \\
\text { C6 }\end{array}$ & $\begin{array}{l}\text { HNE-Cys } \\
\text { HNA-lactone-Cys } \\
\text { HNA-lactone-GSH } \\
\text { DHN } \\
\text { HNA } \\
\text { HNE }\end{array}$ & $\begin{array}{l}\text { ESI/MS (18) } \\
\text { comp. with std } \\
\text { comp. with std } \\
\text { GC/MS } \\
\text { GC/MS } \\
\text { GC/MS }\end{array}$ & $\begin{array}{l}78.5 \pm 3.2 \\
2.0 \pm 1.1 \\
<1 \\
3.3 \pm 0.5 \\
4.5 \pm 0.9 \\
2.8 \pm 0.9\end{array}$ & $\begin{array}{l}77.8 \pm 4.3 \\
1.8 \pm 0.9 \\
<1 \\
3.5 \pm 0.6 \\
4.5 \pm 1.1 \\
3.2 \pm 0.8\end{array}$ \\
\hline
\end{tabular}

a The results are the mean of three individual determinations \pm SD. For HNE-Cys and HNE-GSH, the fragmentation pattern is indicated in the cited reference.

precipitate proteins and then centrifuged (10 000g for $10 \mathrm{~min}$ ). The supernatant was evaporated under vacuum at $45{ }^{\circ} \mathrm{C}$ to about $1 \mathrm{~mL}$, diluted to $10 \mathrm{~mL}$ with distilled water, and brought to $\mathrm{pH} 1-2$ with $1 \mathrm{M} \mathrm{H}_{3} \mathrm{PO}_{4}(200 \mu \mathrm{L})$. The resulting sample was loaded onto a $360 \mathrm{mg}$ C18 Sep Pak Plus cartridge preconditioned with $5 \mathrm{~mL}$ of methanol and $10 \mathrm{~mL}$ of $1 \%(\mathrm{v} / \mathrm{v})$ acetic acid. The cartridge was washed with $10 \mathrm{~mL}$ of $1 \%(\mathrm{v} / \mathrm{v})$ acetic acid, dried under a nitrogen stream, and eluted with $5 \mathrm{~mL}$ of methanol. The eluate was evaporated to dryness under vacuum at $45^{\circ} \mathrm{C}$ and the residue, redissolved in $450 \mu \mathrm{L}$ eluent, was analyzed by HPLC. The radioactive protein pellet was dissolved in $1 \mathrm{~mL}$ of $0.2 \mathrm{M} \mathrm{NaOH}$ and directly counted. Preliminary experiments showed that the amounts of dichloromethane extractable me tabolites formed with $\mathrm{HNE}-\mathrm{MA}$ and $\mathrm{HNE}-\mathrm{Cys}$ as substrates were very low; therefore, the extraction step was deleted for these substrates. The incubation mixture was directly loaded on the C18 cartridge, and the resulting methanolic eluate was evaporated to dryness under vacuum at room temperature and analyzed by HPLC.

\section{Results}

A. In Vitro Metabolism of HNE - Thioether Conjugates. After incubation of rat liver or kidney cytosolic fractions, the three different HNE - thioethers substrates were partially metabolized (Table 1). Radio-HPLC chromatograms of $\mathrm{HNE}-\mathrm{GSH}$ and $\mathrm{HNE}-\mathrm{MA}$ metabolites are shown in Figures 1 and 2, respectively. The radio-HPLC chromatogram of HNE-Cys metabolites (not shown) was qual itatively identical to that of $\mathrm{HNE}-\mathrm{MA}$. About $2 \%$ of the starting radioactive dose remained in the protein pellet. The structure of the different metabolites was obtained by mass spectrometry or by comparison with authentic standards (Table 1 ).

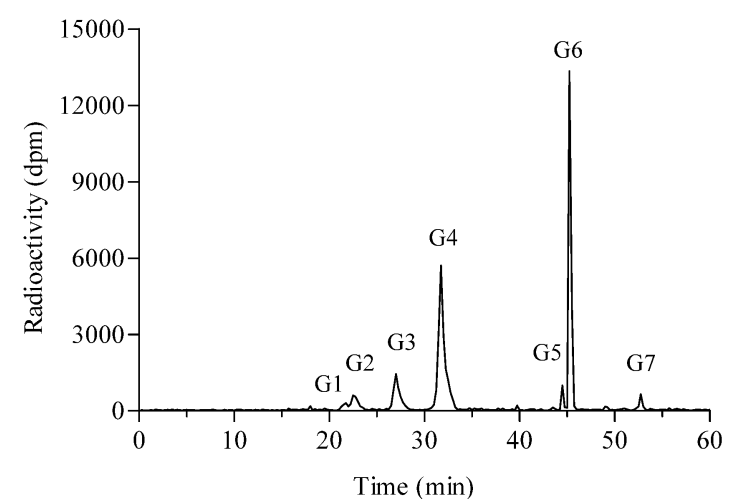

Figure 1. Typical radio-HPLC profile of $\left[4-{ }^{3} \mathrm{H}\right] \mathrm{HNE}-\mathrm{GSH}$ nonextractable metabolites from incubation with rat liver cytosol as described in the Material and Methods section.

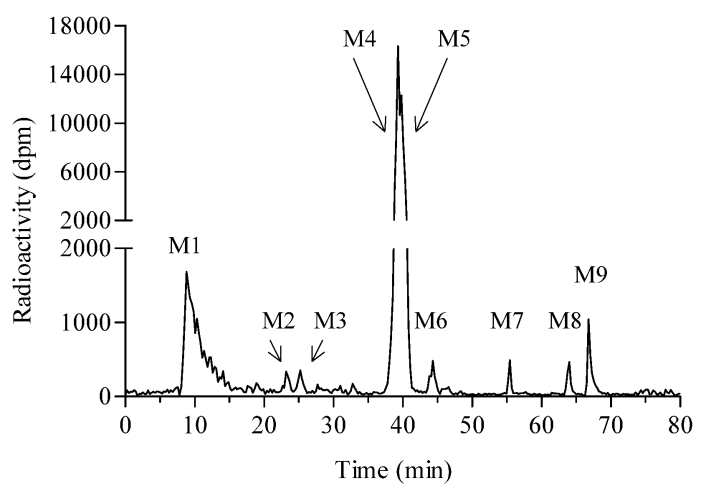

Figure 2. Typical radio-HPLC profile of [4-3H]HNE-MA metabolites from incubation with rat kidney cytosol as described in the Material and Methods section. 
Table 2. ESI/MSn and GC/MS Fragments Ions Observed for HNE-Thioether Metabolites Obtained from Rat Liver and Kidney Cytosolic Fractions and for $\omega$-Hydroxylated HNA-Lactone Obtained with Rat Liver Microsomal Fractiona

\begin{tabular}{|c|c|c|c|c|}
\hline & $\begin{array}{c}\mathrm{ESI} / \mathrm{MS}^{1} \\
\mathrm{~m} / \mathrm{z}\end{array}$ & $\begin{array}{c}\text { ESI/MS2 } \\
\mathrm{m} / \mathrm{z} \text { interpretation }\end{array}$ & $\begin{array}{c}\mathrm{ESI} \mathrm{MS}^{3} \\
\mathrm{~m} / \mathrm{z} \text { interpretation }\end{array}$ & proposed structure \\
\hline G1 & $280[\mathrm{M}+\mathrm{H}]^{+}$ & $262\left[\mathrm{DHN}-\mathrm{Cys}+\mathrm{H}-\mathrm{H}_{2} \mathrm{O}\right]^{+}$ & $\begin{array}{l}244\left[\mathrm{DHN}-\mathrm{Cys}+\mathrm{H}-2 \mathrm{H}_{2} \mathrm{O}\right]^{+} \\
122[\mathrm{Cys}+\mathrm{H}]^{+} \\
141\left[\mathrm{DHN}+\mathrm{H}-\mathrm{H}_{2} \mathrm{O}\right]^{+}\end{array}$ & DHN-Cys \\
\hline G3 & $466[\mathrm{M}+\mathrm{H}]^{+}$ & $\begin{array}{l}448\left[\mathrm{DHN}-\mathrm{GSH}+\mathrm{H}-\mathrm{H}_{2} \mathrm{O}\right]^{+} \\
319\left[\mathrm{DHN}-\mathrm{GSH}+\mathrm{H}-{\text { glutamic acid }]^{+}}^{-}\right.\end{array}$ & & $\mathrm{DHN}-\mathrm{GSH}$ \\
\hline G5 & $276[\mathrm{M}+\mathrm{H}]^{+}$ & $\begin{array}{l}258\left[\mathrm{HNA}-\text { lactone-Cys }+\mathrm{H}-\mathrm{H}_{2} \mathrm{O}\right]^{+} \\
122[\text { Cys }+\mathrm{H}]^{+} \\
155[\mathrm{HNA}-\text { lactone }+\mathrm{H}]^{+}\end{array}$ & & HNA-lactone-Cys \\
\hline $\begin{array}{l}\text { G6 } \\
\text { M2 }\end{array}$ & $460[\mathrm{M}-\mathrm{H}]^{-}$ & $\begin{array}{l}442\left[\mathrm{HNA}-\text { lactone- } \mathrm{GSH}-\mathrm{H}-\mathrm{H}_{2} \mathrm{O}\right]^{-} \\
306[\mathrm{GSH}-\mathrm{H}]^{-}\end{array}$ & & HNA-lactone-GSH \\
\hline G10 & $155[\mathrm{M}+\mathrm{H}]^{+}$ & $\begin{array}{l}137\left[\mathrm{HNA}-\text { lactone }+\mathrm{H}-\mathrm{H}_{2} \mathrm{O}\right]^{+} \\
109\left[\mathrm{CH}_{3}-\mathrm{CH}_{2}-\mathrm{CH}_{2}-\mathrm{CH}_{2}-\right. \\
\quad \mathrm{CH}=\mathrm{CH}-\mathrm{CH}=\mathrm{CH}^{+}\end{array}$ & $\begin{array}{l}81\left[\mathrm{CH}_{3}-\mathrm{CH}_{2}-\mathrm{CH}=\mathrm{CH}-\mathrm{CH}=\mathrm{CH}\right]^{+} \\
67\left[\mathrm{CH}_{3}-\mathrm{CH}=\mathrm{CH}-\mathrm{CH}=\mathrm{CH}\right]^{+}\end{array}$ & HNA-lactone (Figure 3) \\
\hline S & $171[\mathrm{M}+\mathrm{H}]^{+}$ & $\begin{array}{l}153\left[\mathrm{MH}-\mathrm{H}_{2} \mathrm{O}\right]^{+} \\
125\left[\mathrm{HOCH}{ }_{2}-\mathrm{CH}_{2}-\mathrm{CH}_{2}-\right. \\
\left.\quad \mathrm{CH}_{2}-\mathrm{CH}=\mathrm{CH}-\mathrm{CH}=\mathrm{CH}\right]^{+}\end{array}$ & & 9-hydroxy-HNA-lactone \\
\hline \multicolumn{4}{|c|}{$\begin{array}{c}\text { GC/MS } \\
\mathrm{m} / \mathrm{z} \text { interpretation }\end{array}$} & proposed structure \\
\hline \multicolumn{2}{|c|}{ G7 } & \multirow{3}{*}{\multicolumn{2}{|c|}{$\begin{array}{l}243\left[\mathrm{M}-\mathrm{CH}_{3}\right]^{+} \\
227\left[\mathrm{M}-\mathrm{CH}_{3} \mathrm{O}\right]^{+} \\
199\left[\mathrm{M}-\mathrm{CH}_{3}-\mathrm{CO}_{2}\right]^{+} \\
187\left[\left(\mathrm{CH}_{3}\right)_{3}-\mathrm{Si}-\mathrm{O}-\mathrm{CH}=\mathrm{CH}-\mathrm{COOCH}_{3}\right]^{+} \\
287\left[\mathrm{M}-\mathrm{CH}_{3}\right]^{+} \\
231\left[\left(\mathrm{CH}_{3}\right)_{3}-\mathrm{Si}-\mathrm{O}-\mathrm{CH}-\mathrm{CH}=\mathrm{CH}-\mathrm{CH}_{2}-\mathrm{O}-\mathrm{Si}-\left(\mathrm{CH}_{3}\right)_{3}\right]^{+} \\
173\left[\mathrm{CH}_{3}-\left(\mathrm{CH}_{2}\right)_{4}-\mathrm{CHO}-\mathrm{Si}-\left(\mathrm{CH}_{3}\right)_{3}\right]^{+} 199\left[\mathrm{M}-\mathrm{CH}_{2}-\mathrm{O}-\mathrm{Si}-\left(\mathrm{CH}_{3}\right)_{3}\right]^{+} \\
147\left[\left(\mathrm{CH}_{3}\right)_{2}-\mathrm{Si}-\mathrm{O}-\mathrm{Si}-\left(\mathrm{CH}_{3}\right)_{3}\right]^{+} \\
228[\mathrm{M}]^{+\bullet} \\
213\left[\mathrm{M}-\mathrm{CH}_{3}\right]^{+} \\
199\left[\mathrm{M}-\mathrm{CHO}^{+}\right. \\
184\left[\mathrm{M}-\mathrm{CH}_{3}-\mathrm{CHO}\right]^{+\cdot} \\
157\left[\left(\mathrm{CH}_{3}\right)_{3}-\mathrm{Si}-\mathrm{O}-\mathrm{CH}-\mathrm{CH}=\mathrm{CH}-\mathrm{CHO}\right]^{+}\end{array}$}} & HNA \\
\hline & G8 & & & $\mathrm{DHN}$ \\
\hline & G9 & & & HNE \\
\hline
\end{tabular}

a Metabolites in the first column are named as described in Table 1. Metabolite $\mathrm{S}$ is the metabolite obtained during the incubation of HNA-lactone with rat liver microsomal fraction. Bold m/z ions indicate the selected ion for further fragmentation.

The characterization of metabolites was performed by ESI/MS or GC/MS analysis (Table 1), and fragmentation patterns are given in Table 2.

To confirm the structures, the fragmentation was compared to that of an authentic standard. Because of the low available amounts of metabolites obtained with HNE - Cys and HNE-MA as substrates, most of these metabolites were characterized only by comparison of their retention time with those of authentic synthesized standards, and a confirmation of the structure by ESI / $\mathrm{MS}^{\mathrm{n}}$ was performed only when required.

As no authentic standard of HNA - lactone was available for the comparison of metabolite G10 fragmentation pattern (Figure 3) and as Mw 154 could also correspond to that of 4-oxo-nonenal, a possible metabolite of HNE, additional investigations were performed to unambiguously characterize this metabolite. No hydrazone formation occurred when metabolite $\mathrm{G} 10$ was reacted with 2,4dinitrophenylhydrazine in acidic medium, in contrast to what occurs with 4-oxo-nonenal. Moreover, hydrolysis of G10 (0.1 M Na${ }_{2} \mathrm{HPO}_{4}, \mathrm{pH} 8.9,5 \mathrm{~h}, 25^{\circ} \mathrm{C}$ ) afforded $46 \%$ HNA. This chemical behavior together with the fragmentation pattern unambiguously characterize metabolite $\mathrm{G} 10$ as HNA-lactone.

To clarify metabolic pathways, additional incubations were performed in the presence of inhibitor or added cofactor. The more relevant experimental results are summarized below.

A.1. Formation of DHN-GSH from HNE-GSH. I ncubations performed with $\mathrm{HNE}-\mathrm{GSH}$ and rat liver and kidney cytosolic fractions in the presence of $10 \mathrm{mM}$ pyrazole, a potent inhibitor of $\mathrm{ADH}$, or in the presence of added NADH cofactor did not modify the formation of DHN-GSH as compared to that of control incubations. The addition of $0.5 \mu \mathrm{mol}$ of NADPH increased DHN-GSH levels when compared to those obtained in control incubations: 15 vs $6.7 \%$ and 11 vs $5 \%$ with liver and kidney cytosolic fractions, respectively. Incubations performed in the presence of $1 \mathrm{mM}$ phenobarbital resulted in a $40 \%$ inhibition of the HNE-GSH reduction.

A.2. Formation of Oxidized Metabolites. A.2.1. Formation of HNA-Lactone-GSH from HNEGSH. Cytosolic incubations performed with HNE-GSH as substrate in the presence $0.2 \mathrm{mM}$ disulfiram, a potent ALDH (NAD ${ }^{+}$-dependent) inhibitor gave a 95\% depletion of the HNA-lactone-GSH formation, as compared to control incubations.

A.2.2. Formation of HNA-Lactone from HNALactone-GSH. Incubation of HNA-lactone-GSH standard with liver cytosolic fraction, for $2 \mathrm{~h}$ at $37^{\circ} \mathrm{C}$ and $\mathrm{pH}$ 7.5, afforded HNA-lactone at about $10 \%$ of the HNA-lactone-GSH dose.

A.2.3. Formation of HNA-Lactone-GSH from HNA-Lactone. Incubations of HNA-lactone (2 h, 37 ${ }^{\circ} \mathrm{C}$, pH 7.5) with GSH, with or without GSTs, afforded $85 \%$ of HNA-lactone-GSH.

A.2.4. Formation of HNA-Lactone from HNA. When HNA was placed in mild acid conditions (0.05 M $\mathrm{H}_{2} \mathrm{PO}_{4}, 37^{\circ} \mathrm{C}$, overnight), no HNA-lactone formation occurred, while in the same conditions, 4-hydroxynonanoic acid spontaneously lactonized. 


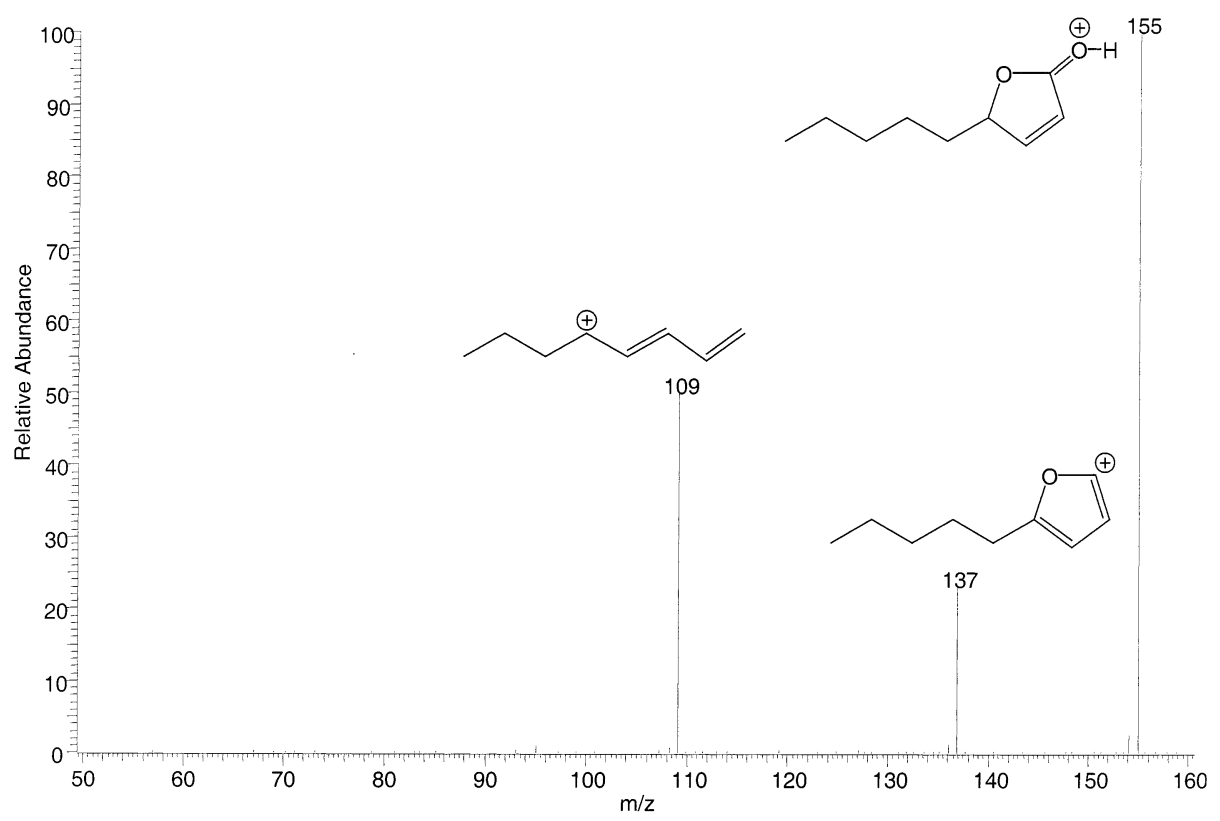

Figure 3. Positive ESI/MS/MS product ion mass spectrum of metabolite G10, the lactone of HNA.

A.2.5. Formation of HNA-Lactone-Cys from HNA-Lactone-GSH or HNE-Cys. Cytosolic incubations performed with HNA-lactone-GSH as substrate gave small amounts of HNA-lactone-Cys. With HNECys standard as substrate in the same conditions, low amounts of HNA-lactone-Cys were also formed.

A.2.6. Origin of HNA-Lactone-MA and HNALactone-GSH from HNA-MA and HNA-GSH, Respectively. In mild acid conditions $\left(1 \mathrm{~h}, 20^{\circ} \mathrm{C}, \mathrm{pH} 2\right)$, the spontaneous lactonization of the two carboxylic acid conjugates occurred with an $80 \%$ yield.

A.2.7. Hydrolysis of HNA-Lactone-GSH, HNALactone-MA, and HNA-Lactone. In physiological conditions $\left(37^{\circ} \mathrm{C}, \mathrm{pH} 7.5,24 \mathrm{~h}\right), \mathrm{HNA}$-lactone-GSH and HNA-lactone-MA afforded $30 \%$ of HNA-GSH and HNA-MA, respectively. In the same conditions, HNAlactone was completely resistant to hydrolysis.

A.3. Retro-Michael Cleavage of HNE - Thioethers. Spontaneous retro-Michael cleavage of HNE-GSH performed in sodium phosphate buffer $\left(2 \mathrm{~h}, 37^{\circ} \mathrm{C}, \mathrm{pH}\right.$ 7.5) afforded $2.2 \%$ of HNE. The same incubation carried out for $1 \mathrm{~h}$ in the presence of 5 units of purified rat liver GSTs afforded increased HNE levels accounting for $9.3 \%$ of the thioether dose. Spontaneous retro-Michael cleavage al so occurred when HNE-MA or HNE-Cys standards were incubated at $37^{\circ} \mathrm{C}(\mathrm{pH} 7.5)$ for $2 \mathrm{~h}$, yielding 2.5 and $10 \%$ HNE, respectively.

B. $\omega$-Hydroxylation of HNA-Lactone. To give insight into the metabolic pathways involved in the formation of $\omega$-hydroxylated MA conjugates previously evidenced in rat urine (21), HNA-lactone ( $50 \mathrm{nmol}$ ) was incubated for $2 \mathrm{~h}$ at $37{ }^{\circ} \mathrm{C}$ and $\mathrm{pH} 7.5$ with rat liver microsomes ( $3 \mathrm{mg}$ proteins) and afforded ( $20 \%$ yield) a compound (S) more polar than HNA-lactone, which was characterized by ESI/MS ${ }^{n}$ as 9-hydroxy-HNA-lactone (Table 2).

\section{Discussion}

The current experimental study provides evidence that rat liver and kidney cytosolic fractions are effective in further metabolizing the primary and major HNE metabolite, namely, HNE-GSH, at the HNE hemiacetal moiety. In contrast, $\mathrm{HNE}-\mathrm{Cys}$ and $\mathrm{HNE}-\mathrm{MA}$, which are secondary metabolites of HNE-GSH, were poorly metabolized at the $\mathrm{C}_{9}$ chain moiety by these cytosolic fractions. The only important metabolization of these two substrates concerns the GSH moiety: HNE-Cys, which originates from $\mathrm{N}$-deacetylation of HNE - MA, was formed in large amounts with kidney cytosolic fractions due to the higher activity of cytosolic $\mathrm{N}$-deacetylases in this organ as compared to the liver $(29,30)$.

These results are consistent with the following in vivo results. First, after HNE injection, $\mathrm{HNE}-\mathrm{MA}$ originating from HNE-GSH only accounted for trace amounts in rat urine (11). Second, in rats injected iv with $\left[{ }^{3} \mathrm{H}\right] \mathrm{HNE}-$ MA, $47 \%$ of the unchanged compound was excreted in the urine (unpublished result). Moreover, it is likely that the results of our in vitro study underestimate the capacity of HNE-GSH to be metabolized by redox reactions, because of the lack of cofactors (NADPH, $\mathrm{NAD}^{+}$) in control incubations.

DHN-MA, the Major Urinary HNE Metabolite Originates from HNE-GSH. DHN-MA, which is present in urine of untreated rats and humans (31), was proposed as a noninvasive biomarker of in vivo lipid peroxidation $(11,12)$. It appears to be of primary importance to experimentally investigate its formation pathways from HNE. DHN - MA originates from DHN-GSH, and this conversion involves $\gamma$-glutamyltranspeptidase, cysteinyl-glycine dipeptidase, and $\mathrm{N}$-acetyltransferases. The activity of the first two enzymes is considered to be lower in rat liver, as compared to kidney $(32,33)$. Moreover, these enzymes are membrane-bound and their presence in the cytosolic fractions most likely results from a slight contamination during the preparation of these subcellular fractions. The results concerning the low amount of $\mathrm{HNE}-\mathrm{Cys}$ as a metabolite of HNE-GSH (Table 1) are consistent with the proposed origin of HNE-Cys.

In the cytosolic incubations performed with HNEGSH as substrate, the major compound resulting from 
reductive metabolism was $\mathrm{DHN}-\mathrm{GSH}$ that reached about $6 \%$ of the incubated dose. Because of the absence of a polarized double bond in $\mathrm{DHN}$, which precludes direct Michael addition of GSH to DHN, several authors $(12,17,23)$ proposed that the formation of DHN-GSH should result from the direct reduction of $\mathrm{HNE}-\mathrm{GSH}$. Our supplementary experiments in the presence of specific inhibitor or cofactor clearly showed that NADH dependent $A D H$ was not involved in the reduction of HNE-GSH to DHN-GSH. In contrast, incubations supplemented with NADPH as reductive cofactor and phenobarbital as inhibitor showed that the enzyme(s) involved in this reduction is cytosolic, NADPH-dependent, and phenobarbital-inhibited, three properties that correspond to aldose reductase, which bel ongs to the AKR superfamily. Indeed, this enzyme purified from bovine lens has been shown to reduce HNE and HNE-GSH to $\mathrm{DHN}$ and DHN-GSH, respectively (34). This enzyme has also been recently implicated in the reduction of HNE GSH to DHN-GSH in aortic endothelial cells (35) and was shown to be more effective in reducing glutathiolated al dehydes than the related free al dehydes (36). However, other data showed that this enzyme is not well-expressed neither in rat nor in human liver $(37,38)$. Nevertheless, the current results clearly characterize DHN-GSH as a metabolite of HNE-GSH when using rat liver cytosolic preparations, and DHN-MA was formally characterized in human urine (31). As aldose reductase and the other members of the AKR superfamily share multiple common properties and overlapping substrate specificites and in the absence of unquestionable data, it must be borne in mind that $A K R(s)$ should be involved in the reduction of HNE-GSH to DHN-GSH. Moreover, it was shown that HNE could induce the expression of another member of the AKR superfamily, namely, al dehyde reductase gene, in rat aortic smooth muscle cells (39). Recently, it was also shown that $A K R 1 C 1$, a human liver $A K R$, could reduce $H N E$ to $D H N$ with even higher efficiency than human liver aldehyde reductase (AKR1A1) (40). However, the efficiency of these enzymes toward HNE-GSH remains to be established.

All Oxidized Mercapturate Derivatives of HNE Originate from the Direct Oxidation of HNE-GSH. In a previous work, we showed that HNA-MA and HNA-lactone-MA were the main MA derivatives from oxidative metabolism of HNE administered in vivo (11). At that time, it was suspected that HNA-lactone-MA was formed by the lactonization of HNA-MA following the exogenous mild acidification $\left(1 \mathrm{~h}, 20{ }^{\circ} \mathrm{C}, \mathrm{pH}\right.$ 2) required for SPE/HPLC procedures (21). In such experimental conditions, chemical lactonization of HNA-GSH standard afforded only $80 \%$ of HNA-lactone-GSH. However, in the current study with HNE-GSH as the substrate incubated with cytosolic fractions, no HNAGSH was found whereas HNA-lactone-GSH accounted for more than $20 \%$ of the radioactive starting dose, suggesting that HNA-lactone-GSH should be formed by an endogenous metabolic pathway. However, at physiological $\mathrm{pH}$, the lactonization of HNA-GSH cannot occur since the $\mathrm{COOH}$ group of HNA-GSH is in the carboxylate form. These two points preclude any endogenous or exogenous formation of HNA-lactone-GSH from HNAGSH. Although HNA is present in the control incubations with $\mathrm{HNE}-\mathrm{GSH}$ as substrate, we cannot hypothesize the formation of HNA-lactone-GSH from HNA since HNA cannot lactonize, even in mild acid conditions because of the presence of the double bond, and cannot be conjugated with GSH, due to the negative charge of the carboxylate at physiological $\mathrm{pH}$. The most likely possibility of HNA-lactone-GSH formation is the direct oxidation of the $\mathrm{CHOH}$ group of the cyclichemiacetal of $\mathrm{HNE}-$ GSH to the corresponding oxo group by cytosolic ALDH $\left(\mathrm{NAD}^{+}\right)$leading to the formation of the lactone group, as confirmed by the additional experiments carried out in the presence of disulfiram, a potent ALDH inhibitor. This pathway is strongly supported by the presence of HNAlactone-GSH in the complete absence of HNA-GSH. This previous formation of the lactone ring implies that the eventual corresponding carboxylic compound originates from the physiological hydrolysis of the lactone ring at $\mathrm{pH} 7.5$.

We show here that HNA-lactone, which is present in our incubations in relatively high amounts, could be at the origin of the polar conjugates found in vivo in the urine of rats administered with HNE (21). Indeed, rat liver microsomal incubations carried out with HNAlactone as substrate show that this compound was $\omega$-hydroxylated. The capacity of HNA-lactone to undergo $\omega$-hydroxylation and the presence in the molecule of polarizable conjugated double bonds required for a conjugation reaction make this compound the most likely candidate for the formation of $\omega$-hydroxylated conjugates.

HNE and HNA-Lactone Thioethers Release the Parent Compounds by Retro-Michael Cleavage. Free metabolites of $\mathrm{HNE}$ - thioether derivatives, namely, HNE, DHN, HNA, and HNA-lactone, were found in the cytosolic incubations with the three HNE-thioethers. Because of the presence of two conjugated double bonds, HNE and HNA-lactone account for soft electrophiles, which give spontaneous Michael addition with thiol compounds and a GST-catalyzed conjugation with GSH . The occurrence of this spontaneous forward reaction implies that of the reverse reaction. On the contrary, because DHN and HNA are not electrophilic compounds, neither the forward addition nor the reverse reaction occurs. With HNE-GSH (HNA-lactone-GSH not tested) as the substrate, our in vitro study showed that the retroMichael reaction was GST-catalyzed, a finding consistent with other GSH conjugates (41-43). Subsequently, the HNE formed by retro-Michael cleavage undergoes direct redox reactions, which accounts for the formation of $\mathrm{DHN}$ and HNA.

The electrophilic compounds HNE and HNA-lactone are exported from the cell and transported el sewhere as thioether conjugates, which can release the active parent compound in physiological conditions. However, in vivo, the retro-Michael cleavage should occur at a low extent, since (i) the GST-catalyzed cleavage of GSH conjugates proceeds intracellularly, where both GSTs and a high level of GSH are local ized; (ii) the ratio of the formation/ cleavage of GSH conjugates is severalfold in favor of the former reaction in physiological conditions, and it can be expected that the levels of free compounds originating from retro-Michael cleavage should remain very low, especially in the case of HNE and HNA-lactone for which the cyclic form of the conjugate stabilizes the structure (44); (iii) in vivo, it can be anticipated that the two major sources of HNE by retro-Michael cleavage, namely, $\mathrm{HNE}-\mathrm{GSH}$ and $\mathrm{HNE}-\mathrm{Cys}$, are readily transformed into HNE-MA, which is a poor substrate for retro-Michael cleavage and is readily excreted in urine; 
Scheme 1. Proposed Metabolic Pathways for the Formation of HNE-GSH Metabolites in Rat Liver and Kidney Cytosolic Fractions (Continuous Line Arrows) and Subsequent In Vivo Reactions (Dotted Arrows)

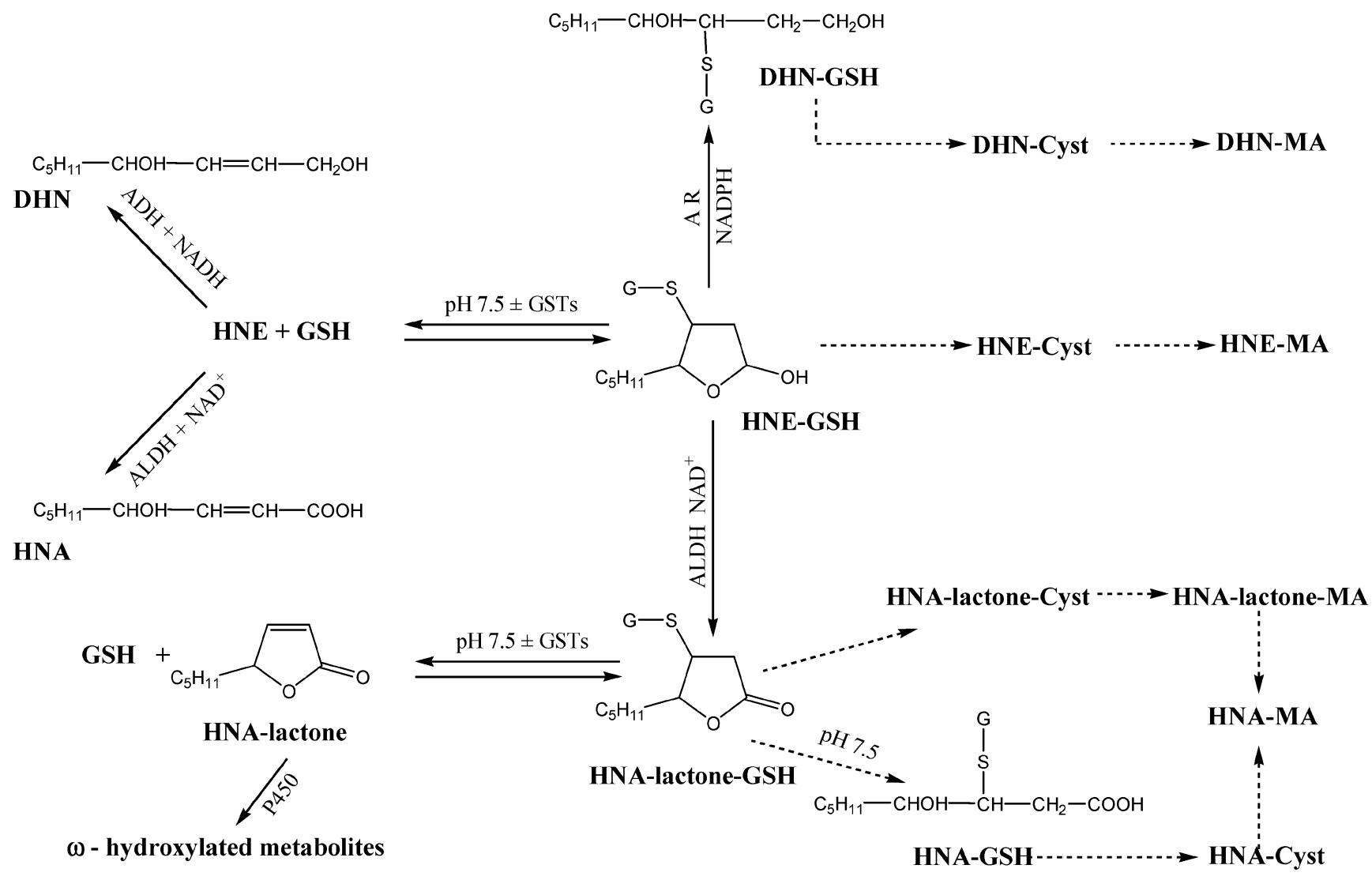

(iv) the fast redox metabolism of $\mathrm{HNE}-\mathrm{GSH}$ removes the unique source of formation of HNE via the retro-Michael reaction. Therefore, with HNE as aglycone, it could be expected that the release should be low. However, in vivo metabolism study of HNE - GSH or HNE-Cys should be undertaken in order to get a more precise insight of the physiological importance of retro-Michael cleavage of HNE - thioethers, which could serve as transport forms because of their low reactivity with other molecules and could increase the half-life of HNE, as it is the case for other GSH conjugates $(45,46)$. These transport forms could then release the "free active forms" elsewhere, possibly far away from where they were gener ated, as it was anticipated by Eisenbrand and co-workers (47) for 2-alkenals.

The current study experimentally points out the mechanisms involved in the formation of the major rat urinary HNE metabolites. Since they were formed, HNE-MA and HNE-Cys were shown to be poor substrates for redox reactions; thus, $\mathrm{HNE}-\mathrm{GSH}$ unquestionably accounts for DHN-MA and HNA-lactone-MA formation. Scheme 1 summarizes the experimentally revealed metabolic pathways that occur in rat liver and kidney cytosols. In the meantime, we have observed that some of the metabolic pathways show stereospecificity (results not shown). This stereospecificity of HNE metabolism could be of physiological importance and is now under investigation.

Acknowledgment. We thank Drs. G. Bories and J . $P$. Cravedi for reviewing the manuscript.

\section{References}

(1) Esterbauer, H. (1982) Aldehydic products of lipid peroxidation. in Free Radicals, Lipid Peroxidation and Cancer (McBrien, D. C. H., and Slater, T. F., Eds.) pp 101-128, Academic Press, London.

(2) Esterbauer, H., Zollner, H., and Schaur, R. J . (1990) Aldehydes formed by lipid peroxidation; mechanisms of formation, occurrence and determination. in Membrane Lipid Oxidation (Vigo-Pelfrey, C., Ed.) Vol. I, pp 239-283, CRC Press, Boca Raton, FL.

(3) Esterbauer, H., J ürgens, G., Quehenberger, O., and Koller, E. (1987) Autoxidation of human low-density lipoprotein: Ioss of polyunsaturated fatty acids and vitamin $\mathrm{E}$ and generation of aldehydes. J. Lipid Res. 28, 495-509.

(4) Eckl, P. M., Ortner, A., and Esterbauer, H. (1993) Genotoxic properties of 4-hydroxyalkenals and analogous aldehydes. Mutat. Res. 290, 183-192.

(5) Esterbauer, H., Schaur, R. J ., and Zollner, H. (1991) Chemistry and biochemistry of 4-hydroxynonenal, malonaldehyde and re lated aldehydes. Free Radical Biol. Med. 11, 81-128.

(6) Esterbauer, H. (1993) Cytotoxicity and genotoxicity of lipidoxidation products. Am. J. Clin. Nutr. 57 (Suppl.), 779S-786S.

(7) Dianzani, M. U., Barrera, G., and Parola, M. (1999) 4-Hydroxy2,3-nonenal as a signal for cell function and differentiation. Acta Biochim. Pol. 46, 61-75.

(8) Parola, M., Bellomo, G., Robino, G., Barrera, G., and Dianzani, M. U. (1999) 4-Hydroxynonenal as a biological signal: molecular basis and pathophysiological implications. Antioxid. Redox Signaling 1, 255-284.

(9) Leonarduzzi, G., Arkan, M. C., Bașağa, H., Chiarpotto, H., Sevanian, A., and Poli, G. (2000) Lipid oxidation products in cell signaling. Free Radical Biol. Med. 28, 1370-1378.

(10) Poli, G., and Schaur, R. J. (2000) 4-Hydroxynonenal in the pathomechanisms of oxidative stress. IUBMB Life 50, 315321.

(11) Alary, I ., Bravais, F., Cravedi, I . P., Debrauwer, L., Rao, D., and Bories, G. (1995) Mercapturic acid conjugates as urinary end metabolites of the lipid peroxidation product 4-hydroxy-nonenal in the rat. Chem. Res. Toxicol. 8, 34-39. 
(12) De Zwart, L. L., Hermanns, R. C. A., Meerman, J. H. N., Commandeur, I . N. M., and Vermeulen, N. P. E. (1996) Disposition in rat of [2-3 $\mathrm{H}$ ]-trans-4-hydroxy-2,3-nonenal, a product of lipid peroxidation. Xenobiotica 26, 1087-1100.

(13) Hartley, D. P., Ruth, J. A., and Petersen, D. R. (1995) The hepatocellular metabolism of 4-hydroxynonenal by alcohol dehydrogenase, aldehyde dehydrogenase and glutathione S-transferase. Arch. Biochem. Biophys. 316, 197-215.

(14) Siems, W. G., Zollner, H., Grune, T., and Esterbauer, H. (1997) Metabolic fate of 4-hydroxynonenal in hepatocytes: 1,4-dihydroxynonene is not the main product. J . Lipid Res. 38, 612-622.

(15) Tjalkens, R. B., Cook, L. W., and Petersen, D. R. (1999) Formation and export of the glutathione conjugate of 4-hydroxy-2,3-nonenal (4-HNE) in hepatoma cells. Arch. Biochem. Biophys. 361, 113119.

(16) Grune, T., Siems, W., Kowal ewski, J ., Zollner, H., and Esterbauer, H. (1991) Identification of metabolic pathways of the lipid peroxidation product 4-hydroxynonenal by enterocytes of rat small intestine. Biochem. Int. 25, 963-971.

(17) Boon, P. J . M., Marinho, H. S., Oosting, R., and Mulder, G. J . (1999) Glutathione conjugation of 4-hydroxy-trans-2,3-nonenal in the rat in vivo, the isolated perfused liver and erythrocytes. Toxicol. Appl. Pharmacol. 159, 214-223.

(18) Laurent, A., Perdu-Durand, E., Alary, J., Debrauwer, L., and Cravedi, J . P. (2000) Metabolism of 4-hydroxynonenal, a cytotoxic product of lipid peroxidation, in rat precision-cut liver slices. Toxicol. Lett. 114, 203-214.

(19) Grune, T., Siems, W. G., and Petras, T. (1997) Identification of metabolic pathways of the lipid peroxidation product 4-hydroxynonenal in in situ perfused rat kidney. J . Lipid Res. 38, 16601665.

(20) I shikawa, T., Esterbauer, H., and Sies, H. (1986) Role of cardiac glutathione transferase and of the glutathione S-conjugate export system in the biotransformation of 4-hydroxynonenal in the heart. J. Biol. Chem. 261, 1576-1581.

(21) Alary, J ., Debrauwer, L., Fernandez, Y., Paris, A., Cravedi, J . P., Dolo, L., Rao, D., and Bories, G. (1998) Identification of novel urinary metabolites of the lipid peroxidation product 4-hydroxy2-nonenal in rats. Chem. Res. Toxicol. 11, 1368-1376.

(22) Guéraud, F., Alary, J ., Costet, P., Debrauwer, L., Dolo, L., Pineau, T., and Paris, A. (1999) In vivo involvement of cytochrome P450 4A family in the oxidative metabolism of the lipid peroxidation product trans-4-hydroxy-2-nonenal, using PPAR $\alpha$-deficient mice. . Lipid Res. 40, 152-159.

(23) Laurent, A., Alary, J ., Debrauwer, L., and Cravedi, J . P. (1999) Analysis in the rat of 4-hydroxynonenal metabolites excreted in bile: evidence of enterohepatic circulation of these byproducts of lipid peroxidation. Chem. Res. Toxicol. 12, 887-894.

(24) Bravais, F., Rao, D., Alary, J ., Rao, R. C., Debrauwer, L., and Bories, G. (1994) Synthesis of 4-hydroxy[4-³H]-2(E)-nonen-1-aldiethylacetal. J . Labeled Compd. Radiopharm. 36, 471-477.

(25) Schauenstein, E., Dorner, F., and Sonnenbichler, J. (1968) U ber die Bindung von 4-hydroxy-2,3-enalen an proteinSH-grupen. $Z$. Naturforsch. 23b, 316-319.

(26) Esterbauer, H. (1970) Kinetics of the reaction of sulfhydryl compounds with alpha-beta-unsaturated aldehydes in aqueous system. Monatsh. Chem. 101, 782-810.

(27) Bories, G. F., Perdu-Durand, E. F., Sutra, J. F., and Tulliez, J. E. (1991) Evidence for glucuronidation and sulfation of zeranol and metabolites (taleranol and zearalanone) by rat and pig hepatic subfractions. Drug. Metab. Dispos. 19, 140-143.

(28) Lowry, O. H., Rosebrough, N. H., Farr, A. G., and Randall, R. J. (1951) Protein measurement with the folin phenol reagent. J . Biol. Chem. 193, 265-273.

(29) Bray, H. G., and J ames, S. P. (1960) The formation of mercapturic acids 4. Deacetylation of mercapturic acids by the rabbit, rat and guinea pig. Biochem. J . 74, 394-397.
(30) Susuki, S., and Tateishi, M. (1981) Purification and characterization of a rat liver enzyme catalysing $\mathrm{N}$-deacetylation of mercapturic acid conjugates. Drug Metab. Dispos. 9, 573-577.

(31) Alary, J ., Debrauwer, L., Fernandez, Y., Cravedi, J . P., Rao, D., and Bories, G. (1998) 1,4-Dihydroxynonene mercapturic acid, the major end metabolite of exogenous 4-hydroxy-2-nonenal, is a physiological component of rat and human urine. Chem. Res. Toxicol. 11, 130-135.

(32) Mclntyre, T. M., and Curthoys, N. P. (1960) The interorgan metabolism of glutathione. Int. J . Biochem. 12, 545, 551.

(33) Hinchman, C. A., Matsumoto, H., Simmons, T. W., and Ballatori, N. (1991) Intrahepatic conversion of a glutathione conjugate to its mercapturic acid. Metabolism of 1-chloro-2,4-dinitrobenzene in isolated perfused rat and guinea pig livers. J . Biol. Chem. 266, 22179-22185.

(34) Srivastava, S., Chandra, A., Bhatnagar, A., Srivastava, S. K., and Ansari, N. (1995) Lipid peroxidation product, 4-hydroxynonenal and its conjugate with GSH are excellent substrates of bovine lens aldose reductase. Biochem. Biophys. Res. Commun. 217, 741-746.

(35) Srivastava, S., Liu, S. Q., Conklin, D. J ., Zacarias, A., Srivastava, S. K., and Bhatnagar, A. (2001) Involvement of aldose reductase in the metabolism of atherogenic al dehydes. Chem. Biol. Interact. 130-132, 563-571.

(36) Ramana, K. V., Dixit, B. L., Srivastava, S., Balendiran, G. K., Srivastava, S. K., and Bhatnagar, A. (2000) Selective recognition of glutathiolated al dehydes by aldose reductase. Biochemistry 39 $12172-12180$.

(37) Hers, H. G. (1960) L-Aldose-reductase. Biochim. Biophys. Acta 37, $120-126$

(38) Srivastava, S., Ansari, N. H., Haiz, G. A., and Das, B. (1984) Aldose and aldehyde reductase in human tissues. Biochem. Biophys. Res. Commun. 217, 741-746.

(39) Koh, Y. H., Park, Y. S., Takahashi, M., Suzuki, K., and Taniguchi, N. (2000) Aldehyde reductase gene expression by lipid peroxidation end products, MDA and HNE. Free Radical Res. 33, 739746.

(40) Burczynski, M. E., Sridhar, G. R., Palackal, N. T., and Penning, T. M. (2001) The reactive oxygen species- and Michael acceptorinducible human aldo-keto reductase AKR1C1 reduces the $\alpha, \beta$ unsaturated aldehyde 4-hydroxy-2-nonenal to 1,4-dihydroxy-2nonene. J . Biol. Chem. 276, 2890-2897.

(41) Chen, J., and Armstrong R. N. (1995) Stereosel ective catalysis of a retro-Michael reaction by class mu glutathione transferases. Consequences for the internal distribution of products in the active site. Chem. Res. Toxicol. 8, 580-585.

(42) Zhang, Y., Kolm, R. H., Mannervik, B., and Talalay, P. (1995) Reversible conjugation of isothiocyanates with glutathione catalysed by human glutathione transferases. Biochem. Biophys. Res. Commun. 206, 748-755.

(43) Meyer, D. J ., Crease, D. J ., and Ketterer, B. (1995) Forward and reverse catalysis and product sequestration by human glutathione S-transferases in the reaction of GSH with dietary aralkyl isothiocyanates. Biochem. J . 306, 565-569.

(44) Esterbauer, H., Zollner, H., and Scholz, N. (1975) Reaction of glutathione with conjugated carbonyls. Z. Naturforsch. 30c, 466-473.

(45) Witz, G. (1989) Biological interactions of $\alpha, \beta$-unsaturated aldehydes. Free Radical Biol. Med. 7, 333-349.

(46) Baillie, T. A., and Slatter, J . G. (1991) Glutathione: a vehicle for the transport of chemically reactive metabolites in vivo. Acc Chem. Res. 24, 264-270.

(47) Eisenbrand, G., Schuhmacher, J ., and Gölzer, P. (1995) The influence of glutathione and detoxifying enzymes on DNA damage induced by 2-alkenals in primary rat hepatocytes and human lymphoblastoid cells. Chem. Res. Toxicol. 8, 40-46. 